\title{
Rosiglitazone modifies the adipogenic potential of human muscle satellite cells
}

\author{
P. De Coppi - G. Milan • A. Scarda • L. Boldrin • \\ C. Centobene • M. Piccoli • M. Pozzobon • C. Pilon • \\ C. Pagano $\cdot$ P. Gamba $\cdot$ R. Vettor
}

Received: 17 February 2006 / Accepted: 19 April 2006 /Published online: 24 June 2006

(C) Springer-Verlag 2006

\begin{abstract}
Aims/hypothesis Satellite cells are responsible for postnatal skeletal muscle regeneration. It has been demonstrated that mouse satellite cells behave as multipotent stem cells. We studied the differentiation capacities of human satellite cells and evaluated the effect of the insulin sensitiser rosiglitazone, a well known peroxisome proliferative activated receptor gamma (PPARG) agonist, on their adipogenic conversion.

Subjects, materials and methods We obtained human satellite cells from human muscle biopsies of healthy
\end{abstract}

Electronic Supplementary Material Supplementary material is available for this article at http://dx.doi.org/10.1007/s00125-0060304-6 and is accessible for authorized users.

Authors P. De Coppi and G. Milan contributed equally to this work.

P. De Coppi $\cdot$ L. Boldrin • M. Piccoli • M. Pozzobon

Paediatric Oncohaematology, Stem Cell Transplantation Unit,

University of Padua,

Padua, Italy

P. De Coppi · P. Gamba

Division of Paediatric Surgery, Department of Paediatrics,

University of Padua,

Padua, Italy

G. Milan $\cdot$ A. Scarda $\cdot$ C. Centobene $\cdot$ C. Pilon $\cdot$ C. Pagano

R. Vettor

Endocrine-Metabolic Laboratory, Internal Medicine,

Department of Medical and Surgical Sciences,

University of Padua,

Padua, Italy

G. Milan $(\bowtie)$

Department of Medical and Surgical Sciences,

University of Padova,

via Ospedale, 105 ,

35128 Padova, Italy

e-mail: gabriella.milan@unipd.it subjects by single-fibre isolation and cultured them under myogenic, osteogenic and adipogenic conditions. Moreover, we compared the morphological features and the adipose-specific gene expression profiling, as assessed by quantitative PCR, between adipocytes differentiated from human satellite cells and those obtained from the stromal vascular fraction of human visceral fat.

Results We proved by morphological analysis, mRNA expression and immunohistochemistry that human satellite cells are able to differentiate into myotubes, adipocytes and osteocytes. The addition of rosiglitazone to the adipogenic medium strongly activated PPARG expression and enhanced adipogenesis in human satellite cells, but did not in itself trigger the complete adipogenic programme. Moreover, we observed a decrease in wingless-type MMTV integration site family member $10 \mathrm{~B}$ and an upregulation of growth differentiation factor 8 expression, both being independent of PPARG activation.

Conclusions/interpretation Human satellite cells possess a clear adipogenic potential that could explain the presence of mature adipocytes within skeletal muscle in pathological conditions such as obesity, type 2 diabetes and ageingrelated sarcopenia. Rosiglitazone treatment, while enhancing adipogenesis, induces a more favourable pattern of adipocytokine expression in satellite-derived fat cells. This could partially counteract the worsening effect of intermuscular adipose tissue depots on muscle insulin sensitivity.

Keywords Adipocytokines - Adipogenesis .

Ectopic fat depot $\cdot$ Insulin resistance $\cdot$ Muscle .

Rosiglitazone $\cdot$ Satellite cells

\author{
Abbreviations \\ $A D I P O Q$ adiponectin, $\mathrm{C} 1 \mathrm{q}$ and collagen domain \\ containing
}




\begin{tabular}{|c|c|}
\hline AM & adipogenic medium \\
\hline CEBPA & CCAAT/enhancer binding protein alpha \\
\hline $\mathrm{Ct}$ & cycle threshold \\
\hline ESM & Electronic supplementary material \\
\hline$A B P 4$ & fatty acid-binding protein 4 \\
\hline FBS & fetal bovine serum \\
\hline$G D F 8$ & $\begin{array}{l}\text { growth differentiation factor } 8 \text {, gene encoding } \\
\text { for myostatin }\end{array}$ \\
\hline$L E P$ & leptin, murin obesity homologue \\
\hline MM & myogenic medium \\
\hline MYOD1 & myogenic differentiation 1 \\
\hline$M Y O G$ & myogenin \\
\hline $\mathrm{OM}$ & osteogenic medium \\
\hline PAX7 & paired box gene 7 \\
\hline PBEF1 & $\begin{array}{l}\text { pre-B-cell colony enhancing factor } 1 \text {, gene } \\
\text { encoding visfatin }\end{array}$ \\
\hline PPARG & peroxisome proliferative activated receptor gamma \\
\hline RETN & resistin \\
\hline$R U N X 2$ & runt-related transcription factor 2 \\
\hline WNT10B & $\begin{array}{l}\text { wingless-type MMTV integration site family } \\
\text { member 10B }\end{array}$ \\
\hline
\end{tabular}

\section{Introduction}

Lipotoxicity could result from NEFA overflow, altered adipose tissue topography, impaired adipocyte function and increase of fat cells in non-adipose organs. Particularly at the skeletal muscle level, both intramyocellular lipids and intermuscular adipose tissue depots directly correlate with the degree of insulin resistance in obese subjects and patients with type 2 diabetes [1-3]. What is the origin of fat cells surrounding muscle bundles? They could derive from different progenitors normally present in the adult skeletal muscle: mesenchymal stem cells, muscle-derived stem cells or satellite cells [4]. After birth, muscle regeneration is mostly mediated by satellite cells, a unique population of committed stem cells located adjacent to the plasma membrane of myofibres [5]. Several studies carried out in animal models have shown that satellite cells give rise to new myotubes, but they can also differentiate into other cells of mesenchymal origin. In particular, it has been shown that in vitro mouse satellite cells can directly differentiate into adipocytes, osteocytes and chondrocytes $[6,7]$. Moreover, thiazolidinediones treatment induces C2C12 myoblasts and satellite cells isolated from normal mice to differentiate into adipocyte-like cells [8].

There is evidence that a balance exists between myogenic and adipogenic differentiation programmes in muscle satellite stem cells and that this balance could be altered in particular pathological conditions. It remains to be determined whether tuning of this regulation contributes to the increased adiposity in muscle.
Peroxisome proliferative activated receptor gamma (PPARG) is the major transcription factor regulating adipogenesis, which results in the acquisition of the mature adipocyte phenotype with the presence of secretory factors collectively called adipokines $[9,10]$.

It has been demonstrated that PPARG overexpression in fibroblasts and the myoblast cell line-G8 was sufficient to develop an adipocyte-like morphology [11, 12], further confirming the fundamental role of PPARG not only in adipogenesis, but also as a factor determining mesodermal cell fate [13].

Other factors have recently been suggested as hypothetical master switches controlling myogenic and adipogenic differentiation programmes. Wingless-type MMTV integration site family member 10B (WNT10B) has been described as a molecular key that blocks the adipogenic programme in mouse preadipocytes, inhibiting the induction of CCAAT/enhancer binding protein alpha (CEBPA) and PPARG [14, 15]. Moreover, the disruption of WNT signalling causes the transdifferentiation of myoblasts into adipocytes in vitro [14].

Myostatin (also known as growth differentiation factor 8 [GDF8]) has been shown to inhibit myogenesis [16] and muscle growth by blocking the activation of satellite cells [17], and to promote the adipogenic differentiation of a multipotent mesenchymal cell line [16]. Moreover, loss of myostatin reduces body fat accumulation [18], although other studies reported that myostatin treatment reduces fat mass in vivo [19] and inhibits 3T3-L1 adipogenic differentiation by decreasing PPARG expression $[19,20]$.

To verify whether muscle adult satellite stem cells are able to differentiate into various mesenchymal lineages in humans, we isolated a population of satellite cells from single myofibres and cultured them to induce in vitro myogenesis, osteogenesis and adipogenesis.

We studied the effect of rosiglitazone treatment on the adipogenic differentiation capacity of human satellite cells and compared the phenotype of fully differentiated adipocytes obtained from human adipose tissue stromal vascular fraction with those from human satellite cells.

\section{Subjects, materials and methods}

Human satellite cells

\section{Cell source and treatment}

Single fibres were isolated from biopsies of human rectus abdominis muscles from three patients (two men, one woman; age 10-25 years) who underwent minor abdominal surgery. We performed one set of cell culture experiments from each subject. 
a

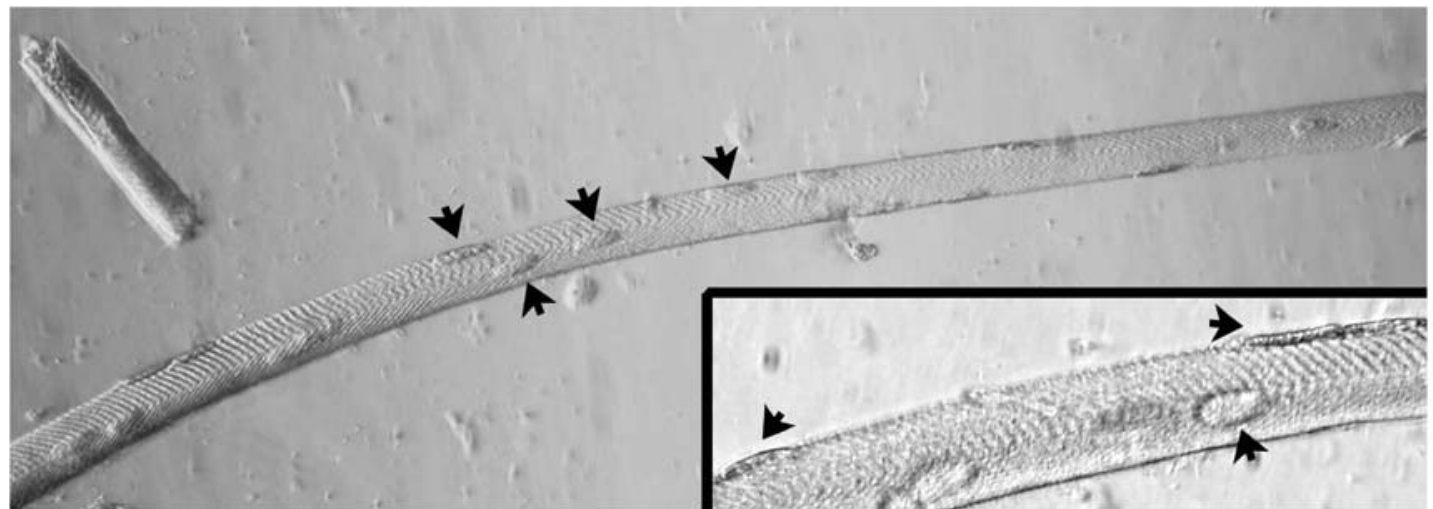

b
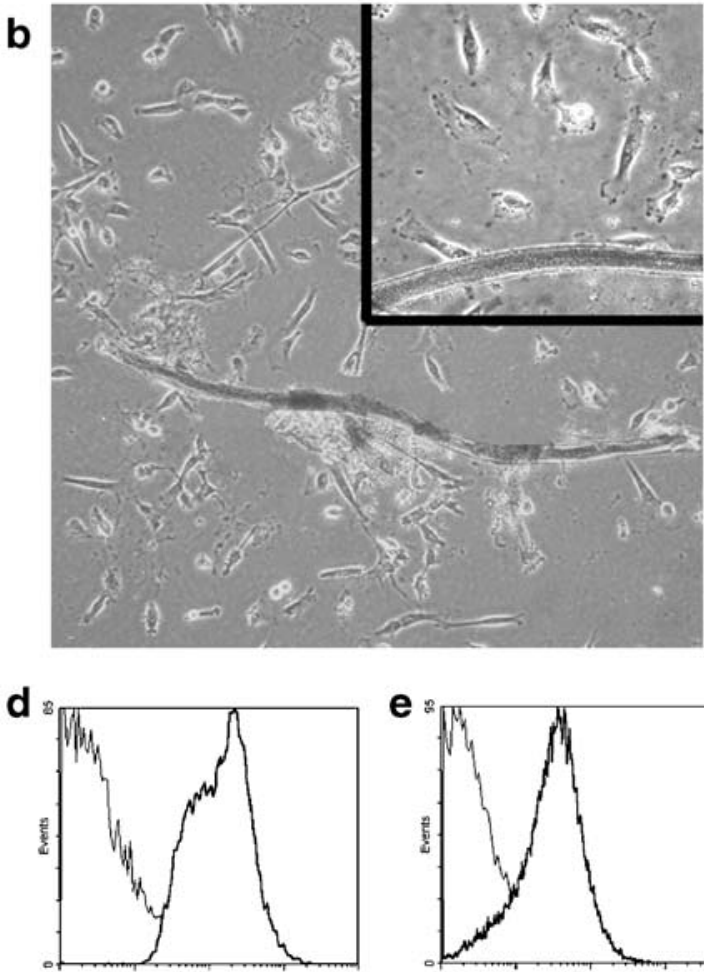

h

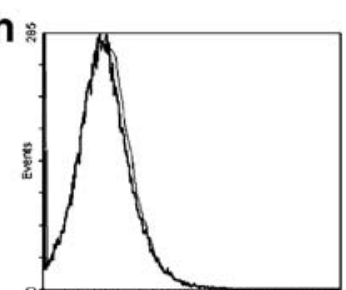

e

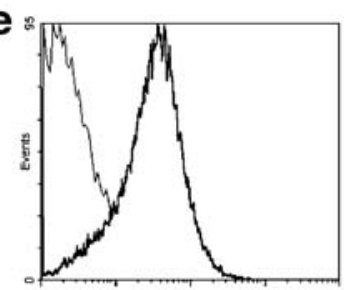

i

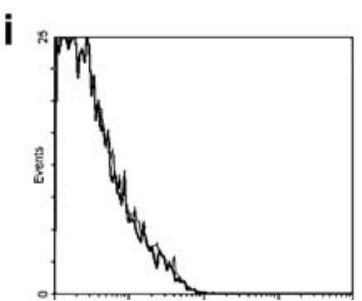

c
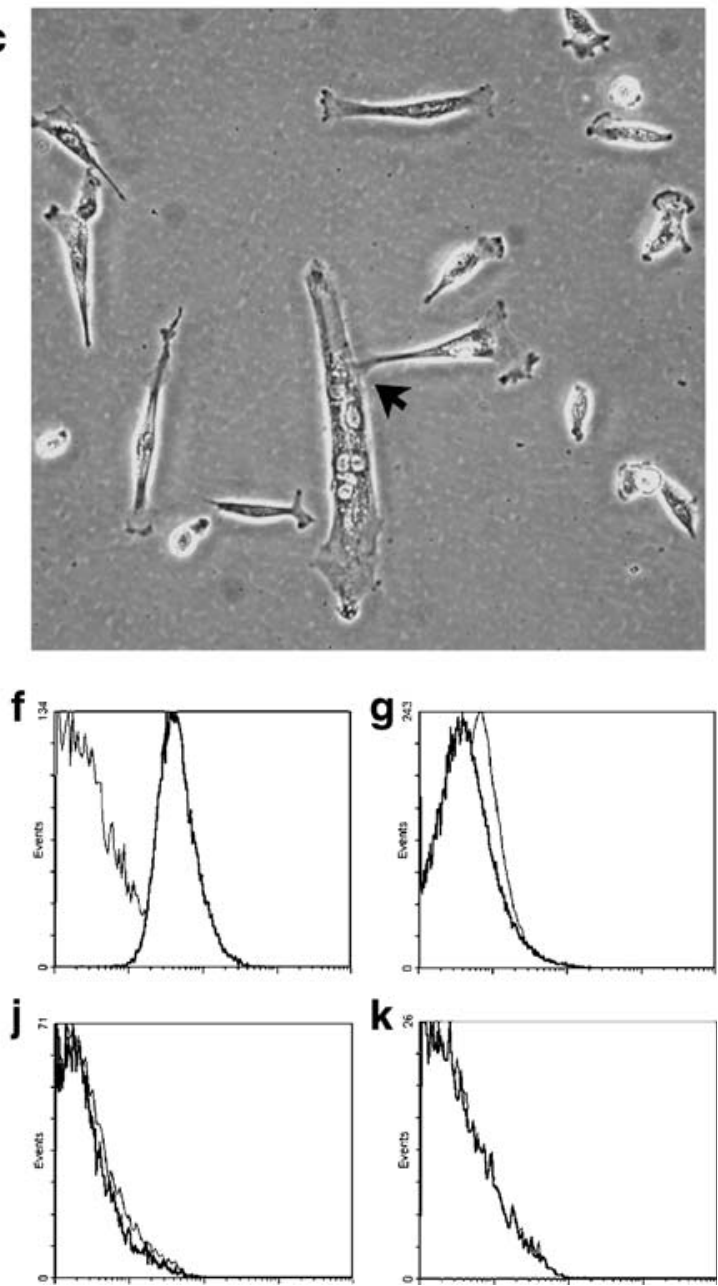

Fig. 1 Characterisation of human satellite cells. a Human satellite cells (arrows) were quiescent and adherent to muscle fibre (b) within 3-4 days, proliferating and (c) fusing to form myotubes (arrow). Human satellite cells were labelled with antibodies against (d) CD44

Donor subjects for muscle and adipose tissue biopsies were otherwise healthy, normal weight, free from endocrine-metabolic alterations and with regular physical activity. Institutional review board approval and informed consent were obtained; the study was carried out in accordance with the Declaration of Helsinki.
(99.4 \pm 0.6), (e) CD56 (81.9 \pm 1.1$)$, (f) HLA-ABC (99.6 \pm 0.3$)$, (g) CD3 (0.63 \pm 0.1$)$, (h) CD4 (0.1 \pm 0.1$)$, (i) CD45 (0.2 \pm 0.3$)$, (j) HLA-DR $(0.1 \pm$ $0.2)$ and $(\mathbf{k}) \mathrm{CD} 31(0.2 \pm 0.2)$ (all in black lines) or with isotype control antibodies (grey lines)

Muscle tissues were processed essentially as previously described by Rosenblatt et al. [21] for rodents and modified by Bonavaud et al. for humans [22]. Briefly, muscles biopsies were rinsed in PBS (GIBCO, Invitrogen LifeTechnologies, Paisley, UK) and digested for $3 \mathrm{~h}$ at $37^{\circ} \mathrm{C}$ with collagenase type I $0.2 \%(\mathrm{w} / \mathrm{v})$ (Sigma-Aldrich, $\mathrm{St}$ 
Louis, MO, USA). Following digestion, the muscles were transferred into plating medium, consisting of DMEM supplemented with $10 \%(\mathrm{v} / \mathrm{v})$ horse serum (GIBCO) and $1 \%(\mathrm{v} / \mathrm{v})$ chicken embryo extract (MP Biomedicals, Irvine, CA, USA). The muscles were triturated with a wide-bore pipette to release myofibres singly selected at an inverted microscope (IX51; Olympus, Tokjo, Japan), placed on dishes pre-coated with $1 \mathrm{mg} / \mathrm{ml}$ matrigel (Falcon, BD Biosciences, San Jose, CA, USA) and incubated at $37.5^{\circ} \mathrm{C}$, $5 \% \mathrm{CO}_{2}$ in a cell culture incubator. The first plate, containing damaged fibres and contaminant cells that normally surround the muscle fibres, such as endothelial cells and fibroblasts, was discharged after selection. Only living fibres were used for the experiments (Fig. 1a).

\section{Cytofluorimetric analysis}

Immunofluorescence was performed using human satellite cells maintained in plating medium for two or three passages, in order to avoid cell fusion and myotube generation. One million human satellite cells were detached using citrate buffer solution (Sigma-Aldrich), washed in PBS and stained for $1 \mathrm{~h}$ at $4^{\circ} \mathrm{C}$ with fluorescein-5isothiocyanate or phycoerythrin-conjugated antibodies against CD3, CD4, CD31, CD44, CD45, CD56, HLAABC, HLA-DR (Immunotech, Marseille, France). Analyses were performed with a Coulter EPICS-XL using EXPO 32 ADC Software (Beckman Coulter, Fullerton, CA, USA).

\section{Myogenic induction}

Five days after seeding, the plating medium was replaced with myogenic medium (MM), consisting of DMEM supplemented by $20 \%$ fetal bovine serum (FBS) (GIBCO), $10 \%$ horse serum and $0.5 \%$ chicken embryo extract. Where indicated (MM+rosiglitazone) $10 \mu \mathrm{mol} / \mathrm{l}$ rosiglitazone (a kind gift from GlaxoSmith Kline) was added to cultures.

\section{Adipogenic induction}

To induce adipogenic differentiation human satellite cells were cultured in adipogenic medium (AM) containing DMEM/F12 supplemented by $10 \%$ FBS, $33 \mu \mathrm{mol} / 1$ biotin, $17 \mu \mathrm{mol} / \mathrm{l}$ pantothenate, $10 \mu \mathrm{g} / \mathrm{ml}$ human transferrin (Sigma-Aldrich), $66 \mathrm{nmol} / 1$ insulin (Lilly Research, Indiana, IN, USA), $100 \mathrm{nmol} / 1$ dexamethasone, $1 \mathrm{nmol} / 1$ triiodothyronine and $0.25 \mathrm{mmol} / \mathrm{l} 3$-isobutyl-1-methylxanthine (Sigma-Aldrich). Where indicated (AM + rosiglitazone) $10 \mu \mathrm{mol} / 1$ rosiglitazone was added to cultures.

\section{Osteogenic induction}

To induce osteogenic differentiation, human satellite cells were cultured in osteogenic medium (OM) consisting of DMEM low glucose, supplemented by $10 \%$ FBS, $1 \%$ antibiotics (GIBCO), $100 \mathrm{nmol} / 1$ dexamethasone, $10 \mathrm{mmol} / 1 \beta$-glycerophosphate (Sigma-Aldrich) and $0.05 \mathrm{mmol} / \mathrm{l}$ ascorbic acid2-phosphate (Wako Chemicals, Irving, TX, USA).

The differentiation media were changed three times per week.

\section{Human preadipocytes}

Abdominal visceral fat was obtained from subjects $(n=5)$ undergoing elective surgery for minor abdominal diseases. One set of cell culture experiments was performed from each subject.

The stromal vascular fraction was isolated from adipose tissue by collagenase type II digestion (1 mg/ml) (SigmaAldrich) in DMEM at $37^{\circ} \mathrm{C}$ for at least $1 \mathrm{~h}$. The sedimented stromal cells obtained by $350 \times g$ centrifugation were resuspended in an erythrocyte-lysing buffer, washed and seeded in DMEM/F12 supplemented by $10 \%$ FBS $\left(0.7 \times 10^{6}\right.$ cells/well in 24-well plates). After 16 to $20 \mathrm{~h}$ for cell attachment, cultures were re-fed with a serum-free AM with or without $10 \mu \mathrm{mol} / \mathrm{l}$ rosiglitazone. 3-Isobutyl-1-methylxanthine and rosiglitazone were removed after 3 days; medium was changed three times per week. Preadipocytes maintained in DMEM/F12 alone were used as controls.

Histochemical staining and immunofluorescence analyses

Alkaline phosphate activity was determined histologically with a leucocyte alkaline phosphatase kit (Sigma-Aldrich).

Lipid droplets were identified by Oil-Red-O staining. Cells were fixed in $10 \%$ formalin (Sigma-Aldrich) for $1 \mathrm{~h}$ at $4{ }^{\circ} \mathrm{C}$ and stained with a $0.5 \%$ solution of Oil-Red-O (SigmaAldrich) in $60 \%$ isopropanol for $15 \mathrm{~min}$ at room temperature.

Human satellite cells were characterised with anti-MyoD (Santa Cruz Biotechnology, Santa Cruz, CA, USA) and anti-Troponin I (Chemicon International, Temecula, CA, USA) antibodies diluted in PBS $2 \%$ BSA. Primary antibody binding was visualised with fluorochrome-conjugated secondary antibodies (Molecular Probes, Invitrogen Labeling \& Detection, Eugene, OR, USA). Cells were counterstained with 4'6-diamidino-2-phenylindole and mounted in aqueous fluorescent mounting media (DakoCytomation, Glostrup, Denmark).

RNA extraction and quantitative PCR determinations

Total RNA was extracted using a kit (RNeasy Mini; Qiagen, Hilden, Germany) following the supplier's instructions. One 


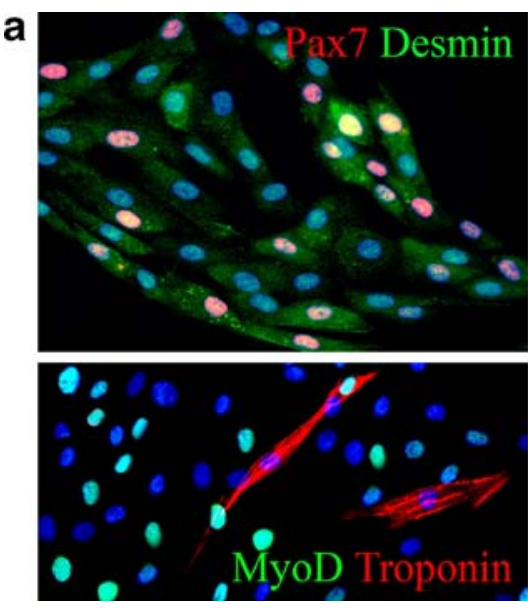

Fig. 2 Multipotency of human satellite cells. a Myogenesis. Myofibres showed positive nuclear staining for MYOD1 (green), expressed troponin (red) and the structural protein desmin (green), while some cells maintained expression of PAX7 (red) as detected by immunofluorescence analysis. b Adipogenesis. Light microscope
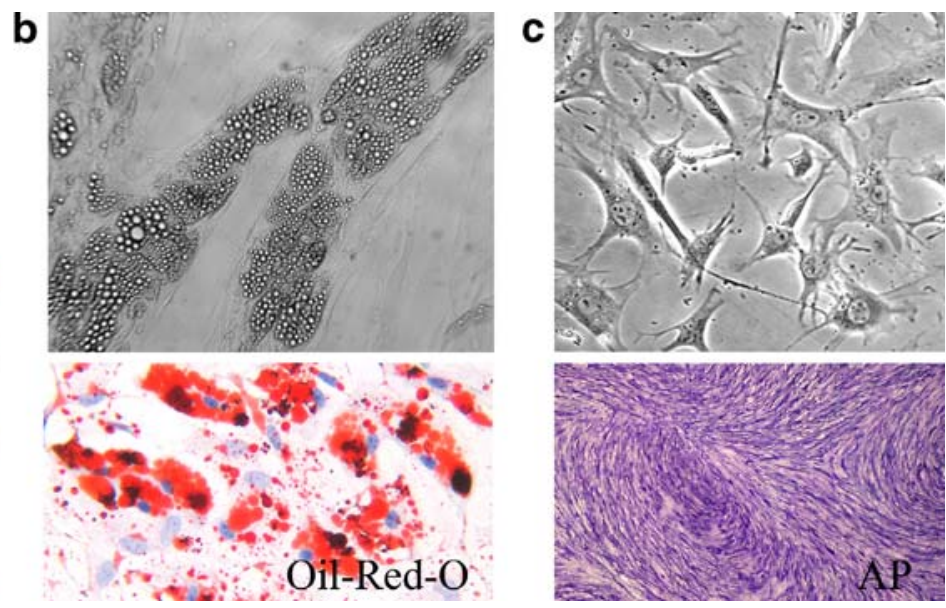

microgram of RNA was treated with DNase treatment and removal reagents (Ambion, Austin, TX, USA) and reversetranscribed for $1 \mathrm{~h}$ at $37^{\circ} \mathrm{C}$ in a $50 \mu \mathrm{l}$ reaction containing $1 \times$ RT buffer, $150 \mathrm{ng}$ random hexamers, $0.5 \mathrm{mmol} / \mathrm{l}$ deoxynucleotide triphosphates, $20 \mathrm{U}$ of RNAsin ribonuclease inhibitor and $200 \mathrm{U}$ of M-MLV RT (Promega Corporation, Madison, WI, USA). Primers sequences and reaction conditions are reported in the Electronic Supplementary Material (ESM) (ESM Table 1). PCR was carried out using a DNA Engine (Opticon 2 Continuous Fluorescence Detection System; MJ Research, Waltham, MA, USA). Reactions were performed two times with SYBR Green PCR Master Mix (Applied Biosystems, Foster City, CA, USA) and 5 to $10 \mathrm{ng}$ of cDNA as previously described [23].

Standard curves were obtained using cDNAs from: (1) skeletal muscle tissue for myogenic differentiation 1 (MYOD1), myogenin (MYOG), growth differentiation factor $8(G D F 8)$ and wingless-type MMTV integration site family member 10B (WNT10B); (2) adipose tissue for $P P A R G 2$, leptin $(L E P)$, adiponectin $(A D I P O Q)$, fatty acidbinding protein $4(F A B P 4)$ and pre-B-cell colony enhancing factor 1 (PBEF1); (3) osteocyte cultures for runt-related transcription factor 2 (RUNX2); and (4) peripheral blood mononuclear cells for resistin $(R E T N)$.

Results were normalised by $18 \mathrm{~S}$ rRNA or hydroxymethylbilane synthase mRNA content and reported as arbitrary units ratio.

\section{Statistical analysis}

Results are presented as mean \pm SD. Statistical analysis was assessed using unpaired $t$-tests or by ANOVA when required. analysis and Oil-Red-O staining showed lipid droplets after 2 weeks in adipogenic medium (200× magnification). c Osteogenesis. Cells formed finger-like excavations, an osteoblast-like appearance (upper panel, 200× magnification) and were positive upon alkaline phosphatase (AP) staining

\section{Results}

Characterisation of human satellite cells

Satellite cells migrated out of the original fibre and proliferated in culture generating 50 to 200 cells surrounding the fibres within 3 to 4 days (Fig. 1b). After 7 to 10 days in culture, when cell density had increased, cells fused to form myotubes (Fig. 1c).

We further characterised the phenotype of human satellite cells by cytofluorimetric analysis. We found that they expressed CD44 and CD56, both well-known markers of satellite cells, and HLA-ABC, and were also negative for specific haematopoietic antigens such as CD3, CD4, CD45 and HLA-DR. CD31-negative staining ruled out the possibility of any endothelial cell contamination (Fig. 1d-k).

Human satellite cells may enter different mesenchymal differentiation pathways

To investigate the differentiation capability of human satellite cells, we cultured them in appropriate media to induce myogenic (in MM), adipogenic (in AM) or osteogenic (in $\mathrm{OM}$ ) phenotypes.

When maintained in MM, human satellite cells produced MYOD1 and started fusing and forming elongated multinucleated myotubes that were positive for troponin as detected by immunofluorescence staining. Human satellite cells showed production of the structural marker desmin and the early myogenic transcription factor PAX7 (Fig. 2a).

Human satellite cells cultured in AM progressively changed their morphology into a round shape. After 14 days in culture, more than $20 \%$ of the cells were filled up with 
Fig. 3 Effect of rosiglitazone on myogenic and adipogenic human satellite cell differentiation. Human satellite cells were cultured in myogenic medium (MM) and in adipogenic medium (AM) with or without $10 \mu \mathrm{mol} / 1$ rosiglitazone (rosi) and analysed under a light microscope $(200 \times$ magnification)
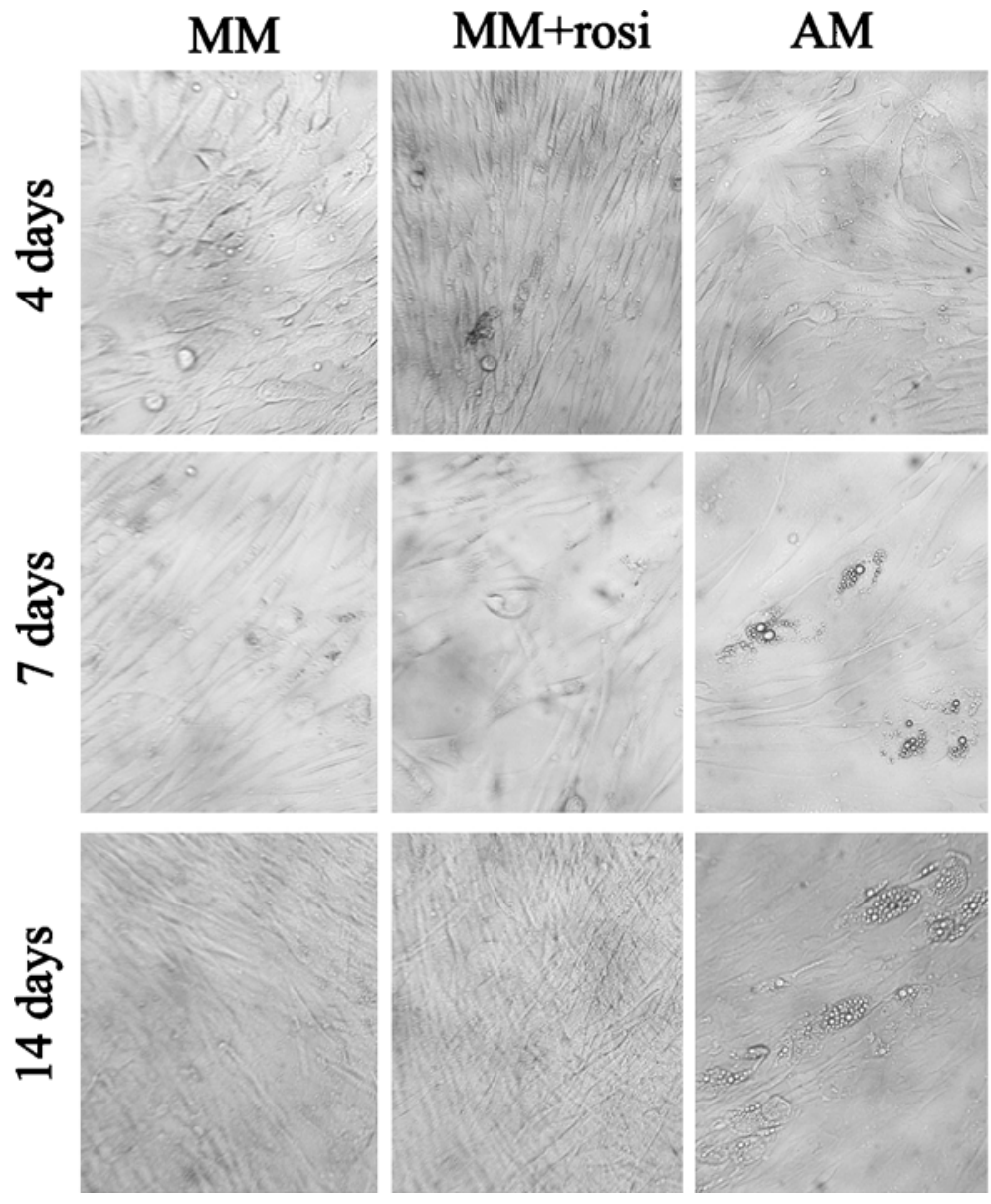

AM+rosi
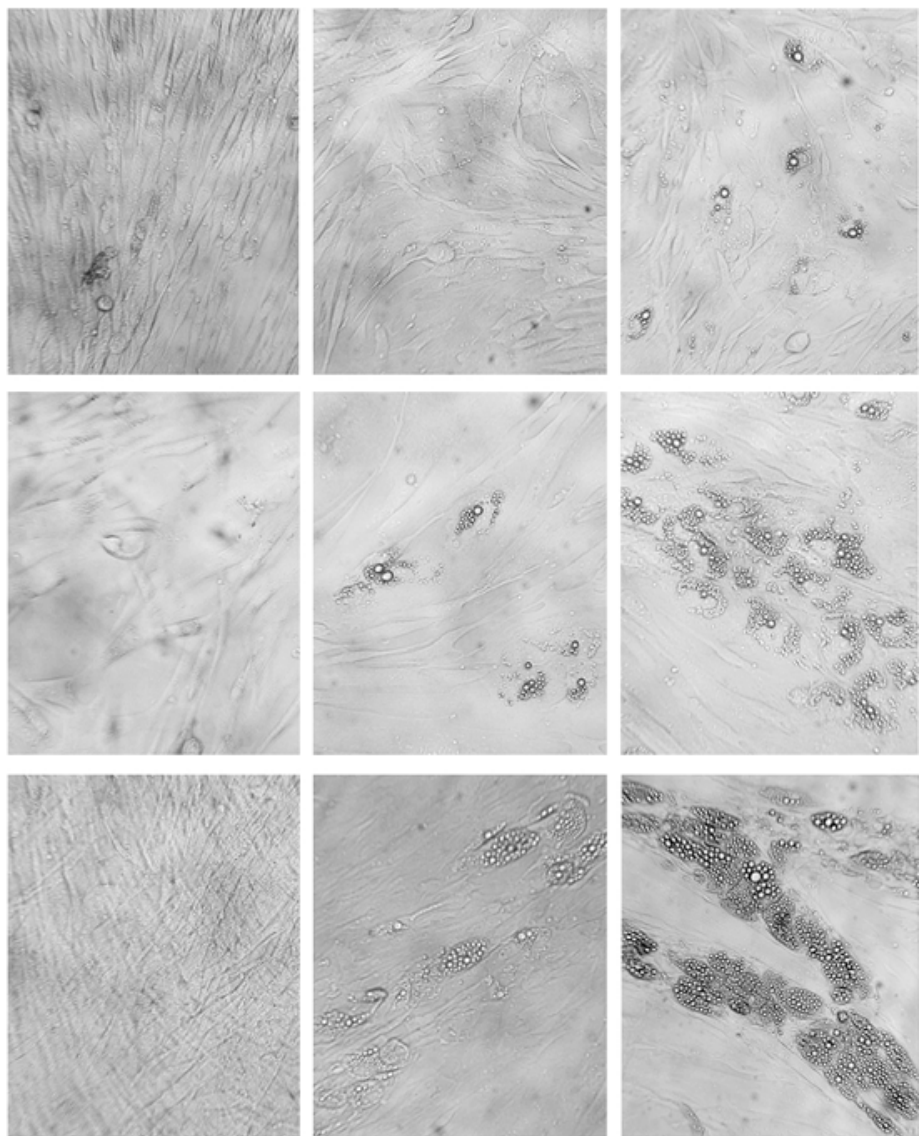
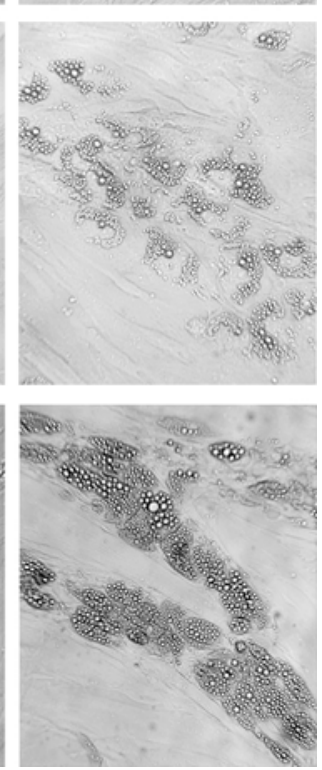

lipid droplets, which positively stained with Oil-Red-O (Fig. 2b).

Light microscopy analysis showed that morphologically $50 \%$ of human satellite cells cultured for 4 days in OM were completely changed, developing an osteoblast-like appearance with finger-like excavations into the cytoplasm; after 14 days they were intensely positive for alkaline phosphate chemical staining (Fig. 2c).

To track the specific mesenchymal development, we quantified MYOD1 and MYOG (an early and late marker of myogenic differentiation), $L E P$ and $A D I P O Q$ (adiposespecific genes) and $R U N X 2$ (a gene upregulated in osteoblast and hypertrophic chondrocytes) expression by quantitative PCR in all satellite cell cultures at different time points.

ESM Fig. 1a,d shows that myogenesis-related genes were upregulated in the three culture conditions with a significantly higher expression (4.16-fold increase for MYOD1 and 6.07-fold increase for MYOG by day 14) in the human satellite cells cultured in AM than in those maintained under $\mathrm{MM}$ or $\mathrm{OM}$ conditions. On the other hand, adipogenic markers were induced in the human satellite cells only under adipogenic conditions, while
$R U N X 2$ expression increased only in OM medium (ESM Fig. 1b,c,e).

Effect of rosiglitazone on human satellite cell differentiation

Human satellite cells cultured in MM proliferate and progressively fuse to form myotubes. The addition of rosiglitazone did not modify their rate of proliferation or their myogenic differentiation capacity, as assessed by light microscope analysis (Fig. 3).

Upon incubation of human satellite cells with AM, 5 to $10 \%$ of the cells became adipocyte-like cells, an effect that was clearly evident after 7 days. The addition of rosiglitazone greatly accelerated the appearance of adipocyte-like cells, this being detectable after only 4 days of treatment, and strongly increased the number of human satellite cells that differentiated into mature adipocytes to 40 to $50 \%$ of the total number of cells, as depicted in Fig. 3.

Figure $4 \mathrm{a}$ shows that rosiglitazone treatment of human satellite cells cultured in MM did not result in any detectable increase of PPARG2 mRNA expression. In contrast, the increased number of adipocyte-like cells 
a

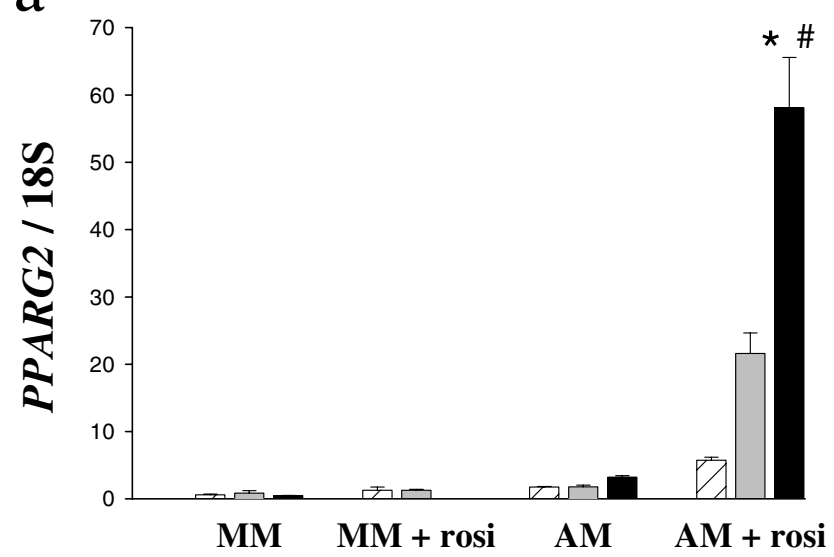

b

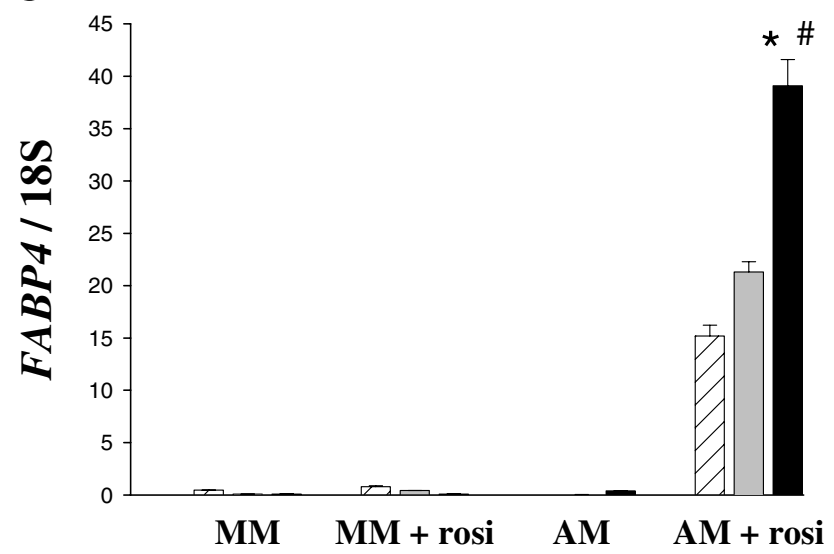

C

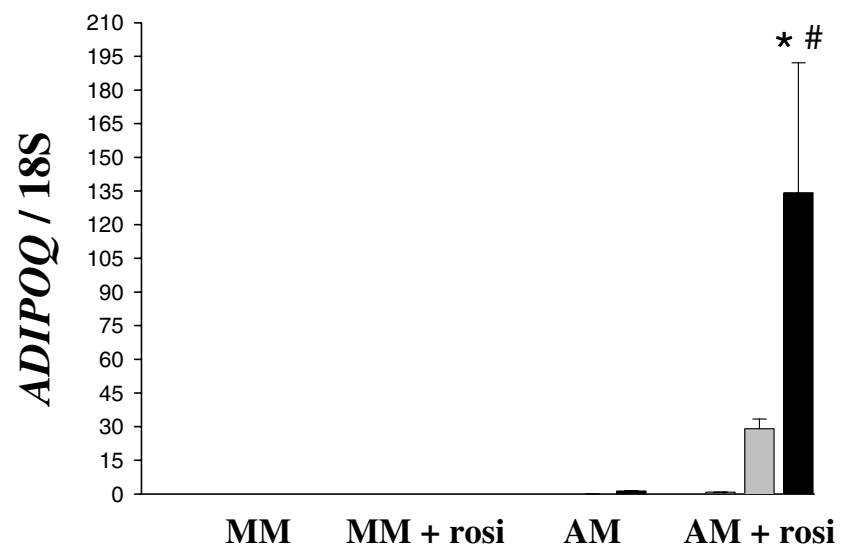

Fig. 4 Quantification of adipose-specific genes in human satellite cells. Quantification of mRNA of PPARG2 (a), FABP4 (b), ADIPOQ

induced by $\mathrm{AM}$ was accompanied by an increase of PPARG2 expression, which was more pronounced when rosiglitazone was added to the AM, resulting in a ten-fold elevation by day 14 (Fig. 4a). Similar results were obtained for PPARG-regulated genes FABP4 and ADIPOQ (Fig. 4b,

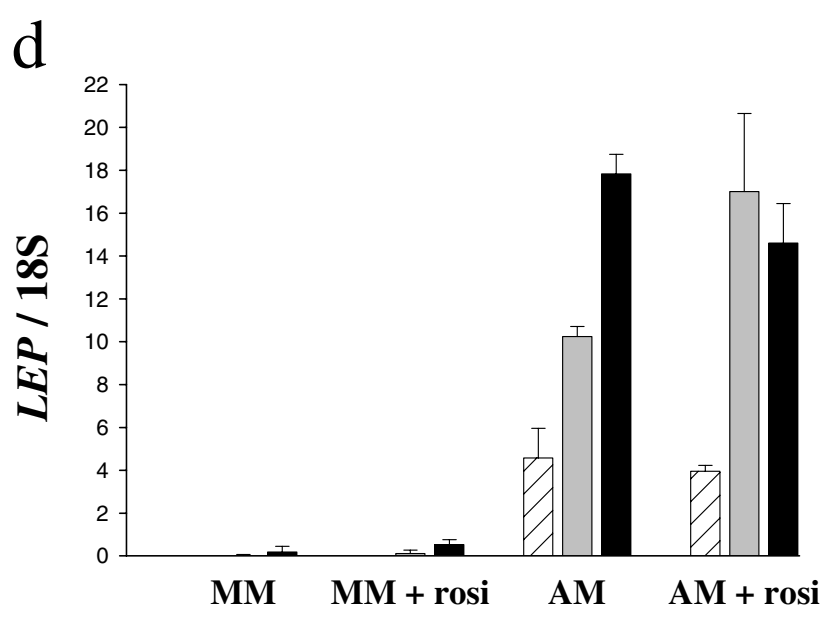

e

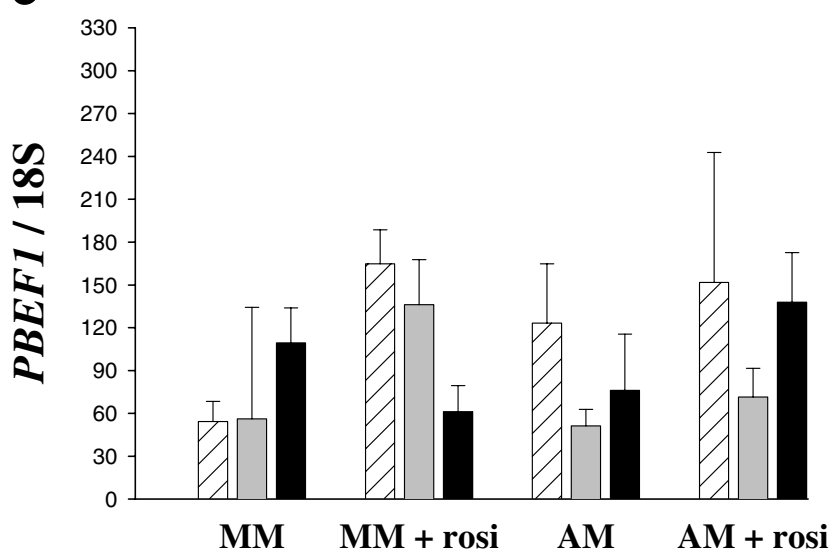

(c), LEP (d) and PBEF1 (e) after 4 (hatched bars), 7 (grey bars) and 14 days (black bars) in myogenic medium (MM) or adipogenic c). On day 14 , in particular, the addition of rosiglitazone to AM increased FABP4 and $A D I P O Q$ expression by about 100 -fold. Against this, the increase in $L E P$ expression was very similar, regardless of whether rosiglitazone was present in AM or not (Fig. 4d). 

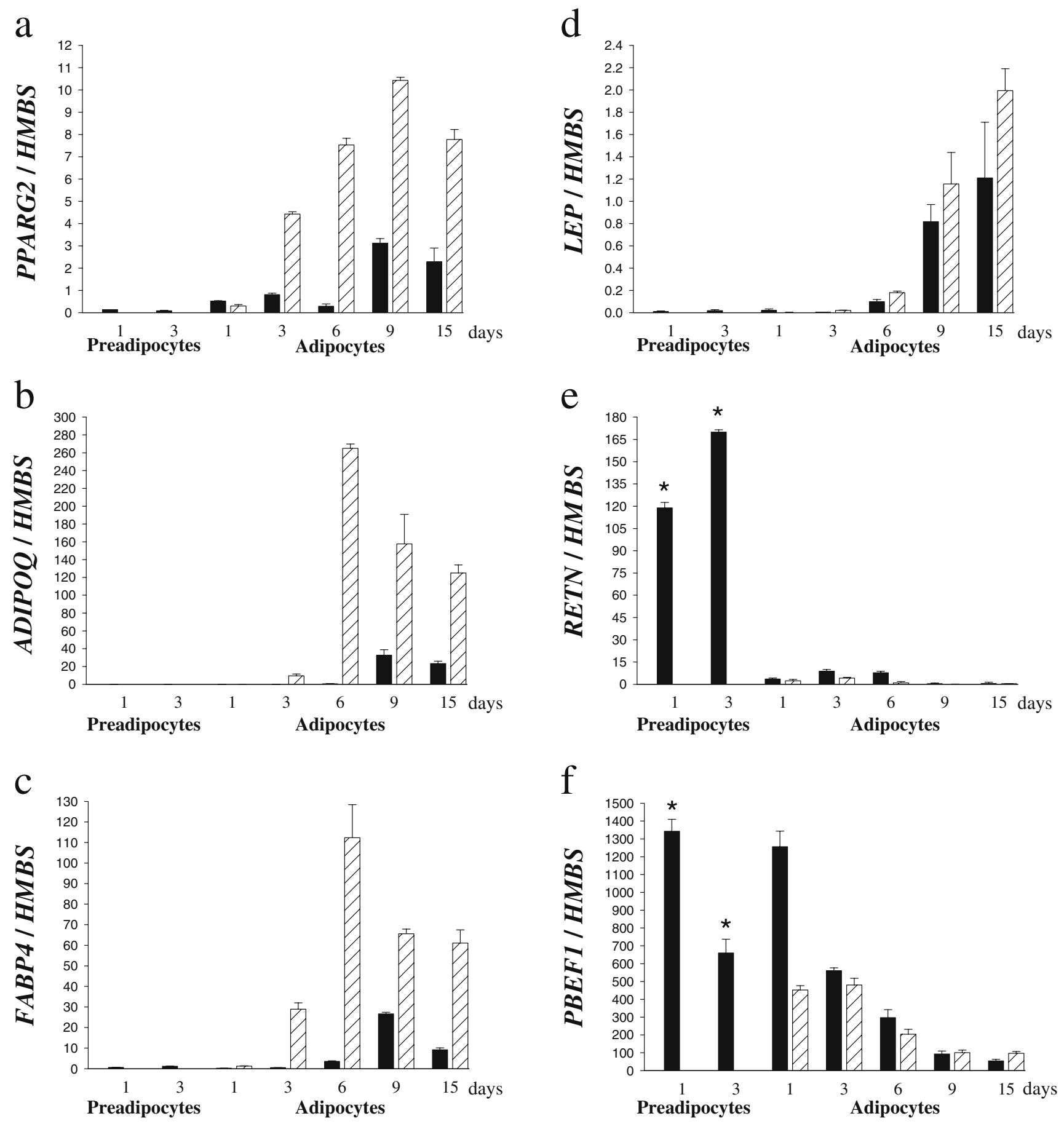

Fig. 5 In vitro differentiation of human preadipocytes and quantification of adipose-specific gene expression. PPARG2 (a), ADIPOQ (b), FABP4 (c), LEP (d), RETN (e) and PBEF1 (f) mRNAs were quantified at different days during adipogenic differentiation. Preadipocytes cultured in basal medium served as controls; adipocytes were cultured in

Among adipocytokines involved in insulin resistance, we evaluated gene expression of RETN (gene encoding resistin) and $P B E F 1$ (gene encoding visfatin). RETN expression was undetectable in all culture conditions analysed. On the other hand, we measured a high level of PBEF1 mRNA in human

adipogenic medium without (black bars) or with $10 \mu \mathrm{mol} / 1$ rosiglitazone (hatched bars). HMBS, hydroxymethylbilane synthase. ${ }^{*} p<0.05$ vs day 15 . Time-dependent changes between the two treatments were significant by ANOVA $(p<0.05)$ for panels $\mathbf{a}, \mathbf{b}$ and $\mathbf{c}$

satellite cells, comparable to that measured in the same amount of cDNA obtained from adipose tissue and used as standard. This high level was found, without changes during myogenic or adipogenic differentiation, and both with and without rosiglitazone (Fig. 4e). 

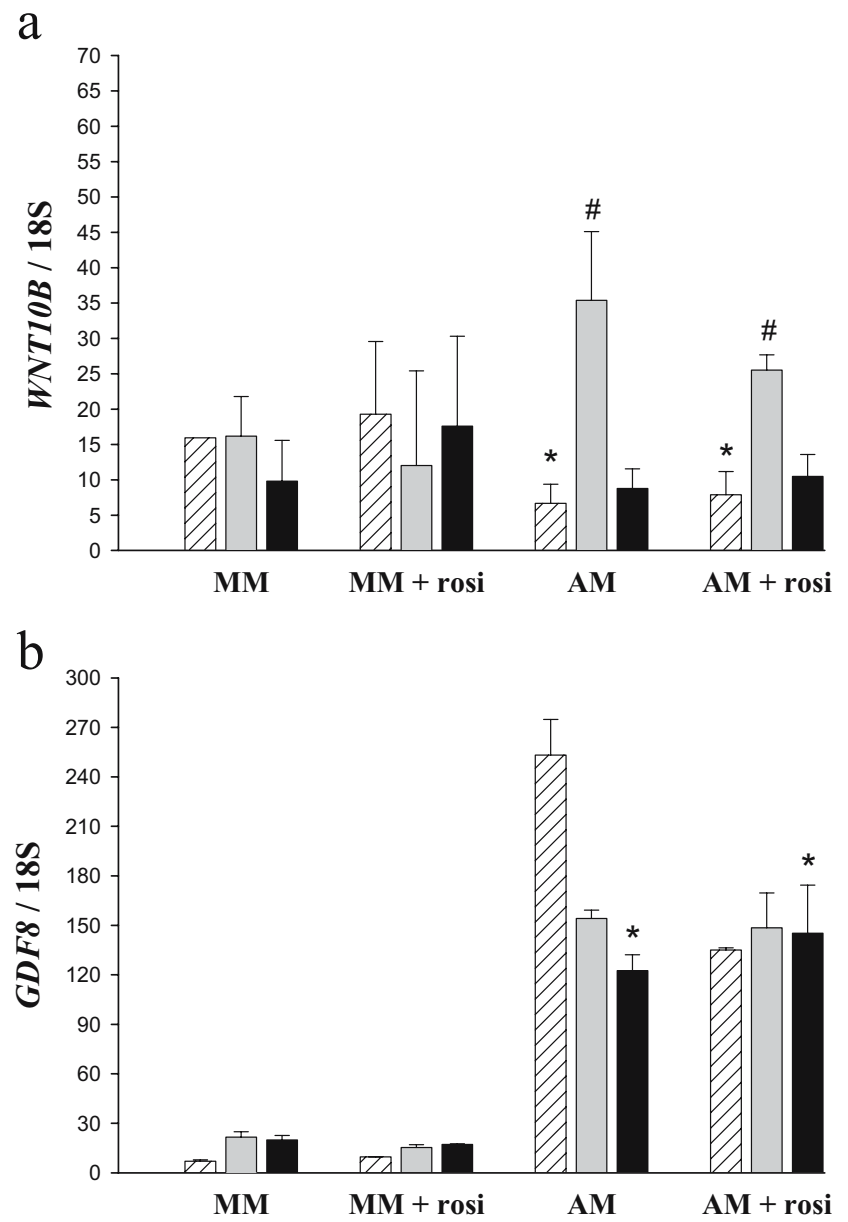

Fig. $6 W N T 1 O B$ and $G D F 8$ expression in human satellite cells during myogenic and adipogenic differentiation. After 4 (hatched bars), 7 (grey bars) and 14 days (black bars) in myogenic medium (MM) or adipogenic medium (AM), with or without $10 \mu \mathrm{mol} / 1$ rosiglitazone (rosi), the mRNA levels of WNT10B (a) and GDF8 (b) were quantified. ${ }^{*} p<0.05$ vs the same day in $\mathrm{MM} \pm$ rosiglitazone; $\# p<0.05$ vs days 4 and 14 of the same medium

Adipose-specific gene expression profiling of adipocytes obtained from adipose tissue

The expression of the same genes analysed in fat cells derived from human satellite cells was measured in adipocytes differentiated from the human adipose tissue stromal vascular fraction. As seen in ESM Fig. 2, the percentage of fully differentiated adipocytes was greater in the presence of rosiglitazone. PPARG2 expression (Fig. 5a) was low in preadipocytes, increased during the early steps of differentiation, and was strongly upregulated, along with expression of PPARG-regulated genes, by the addition of rosiglitazone (Fig. 5b,c). The time course of the rise in $L E P$ mRNA was similar in adipocytes differentiated with or without rosiglitazone (Fig. 5d).

RETN expression was very low in cells isolated from the human adipose tissue stromal vascular fraction (cycle threshold [Ct] 37-40) compared with immune cells used as standard ( $\mathrm{Ct}$ 34-35). On the other hand, PBEF1 expression was as elevated in adipocytes cultured in vitro (Ct 20-24) as it was in adipose tissue specimens (Ct 25). The expression of both these adipocytokines was higher in preadipocytes and declined during adipogenic differentiation, as reported in Fig. 5e,f.

$W N T 10 B$ and $G D F 8$ expression in human satellite cells

Figure 6a shows that $W N T 10 B$ expression at the first time point analysed (4 days) was lower in human satellite cells grown in AM than in those grown in MM. After a pronounced increase in $W N T 10 B$ expression at day 7 ( $\mathrm{AM} \pm$ rosiglitazone), a sharp decline to the basal levels was observed at day 14 (AM \pm rosiglitazone), independently of whether rosiglitazone was present in the medium or not. On the other hand, the expression levels of WNT10B did not change during myogenic differentiation.

With regard to $G D F 8$, a slight increase in expression was observed in MM (Fig. 6b), which was independent of the presence of rosiglitazone. GDF8 mRNA was significantly higher in human satellite cells cultured in AM than in those cultured in MM.

\section{Discussion}

The experimental procedure we used led to the isolation of a cell population from human skeletal muscle, which possesses all phenotypic markers of satellite stem cells that give rise to different mesenchymal lineages, such as fully differentiated adipocytes, osteocytes and myofibres.

Myotubes, as well as adipocytes and osteocytes, obtained from human satellite cells disclosed tissue-specific morphological features and gene expression profiles. Thus, the multipotency of human satellite cells could be a possible mechanism to explain the ectopic bone and fat formation that has been described within skeletal muscle [3, 24].

When the AM was added to the human satellite cells, the myogenic markers dramatically increased, together with the activation of adipogenic-specific genes. This behaviour could be explained in part by the simultaneous growth of both myotubes and fat cells and in part by the presence in the AM of hormones and substrates that are well recognised to work also as muscle growth factors [25, 26].

Adipocytes coming from the human adipose tissue stromal vascular fraction and those coming from human satellite cells share very similar morphological characteristics and adipose-specific gene expression during the different stages of adipogenic differentiation. This observation led us to conclude that properly differentiated adipocytes can be derived from human satellite cells. 
PPARG is a master transcription factor in adipogenesis; its expression increases during the conversion of preadipocytes to adipocytes and it is upregulated by rosiglitazone [9].

PPARG mRNA content was negligible in human satellite cells even when rosiglitazone was added to the MM and the formation of fully differentiated myotubes was unaffected as previously reported [27]. Moreover, the addition of rosiglitazone to human satellite cell cultures did not lead to triglyceride accumulation or the expression of specific adipogenic markers. Other authors have reported that chronic treatment of muscle cell cultures with troglitazone induced expression of adipose-specific genes, but they failed to detect any morphological feature characteristic of a fat cell, further indicating that thiazolidinediones do not induce transdifferentiation [27, 28]. However, in the present study, under adipogenic conditions, human satellite cells expressed PPARG and this expression was further upregulated by rosiglitazone treatment in parallel with the enhancement of their adipogenic differentiation.

Taken together, these findings suggest that rosiglitazone is not sufficient in itself to convert human satellite cells to adipocytes, in contrast with previous observations in a mouse myoblast cell line and in mouse satellite cells [8].

On the other hand, our results underline the fundamental role of PPARG activation in triggering and regulating the adipogenic programme also in human satellite cells. Previous studies reported that G8 myoblasts, when infected with both PPARG and CEBPA retroviral vector cultured in AM, transdifferentiate into mature adipocytes [12]. Moreover, adipogenesis did not occur in PPARG-deficient embryonic stem cells in vivo or in vitro [29], thus suggesting that $P P A R G$ is probably the master gene that commits multipotent mesenchymal stem cells to the adipogenic lineage.

The addition of rosiglitazone to the AM also increased the expression of genes transcriptionally activated by PPARG, namely FABP4 and $A D I P O Q$, in human satellite cells.

$A D I P O Q$ mRNA was undetectable in human satellite cells under myogenic conditions, but its expression may be turned on by PPARG activation, as seen when human satellite cells were cultured in AM and to a greater extent when rosiglitazone was added to the AM.

In contrast, rosiglitazone did not further increase $L E P$ mRNA levels, which would have been expected from the great acceleration of adipogenesis. This is in keeping with findings showing that PPARG activation inhibits $L E P$ gene transcription in 3T3-L1 preadipocytes [30] and human adipocytes [31].

We analysed changes in mRNA expression of two other adipocytokines related to development of obesity and insulin resistance: visfatin and resistin [32-34].

We showed that human satellite cells express $P B E F 1$ at similar levels in all culture conditions used. Moreover, the lack of effect of rosiglitazone on gene encoding for visfatin expression could suggest that this adipokine is not modulated by PPARG activation in contrast to what was recently reported in rosiglitazone-treated OLETF rats [35].

PBEF1 and RETN expression was higher in human preadipocytes than in mature adipocytes differentiated from the human adipose tissue stromal vascular fraction, with the former slightly decreasing its expression during differentiation, and the latter being quite undetectable in mature fat cells.

These results are in keeping with reports in which RETN expression is only occasionally observed in human adipose tissue biopsies and undetectable in human mature adipocyte cultures [36-38], and they lead us to conclude that resistin should not be considered as a marker of fully differentiated adipocytes.

A number of genes have been implicated in the commitment of mesenchymal stem cells to a myogenic or adipogenic lineage. Among them, WNT proteins are important in muscle development [39, 40], and in particular the WNT10B isoform seems to play a crucial role in impeding adipogenesis, partly by inhibiting $P P A R G$ expression in preadipocytes and in adult myoblasts $[14,15,41]$. The role of WNT1OB in the pathophysiology of obesity was recently highlighted by the identification in a severely obese subject of a missense variant, which abrogated the ability of this protein to block adipogenesis [42].

Human satellite cells cultured under adipogenic conditions showed a biphasic pattern with an early increase followed by a drop in $W N T 1 O B$ mRNA content, this effect being independent of PPARG activation obtained by rosiglitazone treatment. This is consistent with an early acceleration of myogenesis, proved by high levels of $M Y O D 1$ and $M Y O G$ expression, which was overcome by the preferential conversion of human satellite cells into adipose cells. In contrast, human satellite cells cultured to form myotubes continued to express $W N T 10 B$ during their differentiation process. These data are consistent with the idea that WNT signalling is implicated in the initiation of myogenesis and the maintenance of muscle phenotype, and that it is an effective inhibitor of adipogenesis in human satellite cells. In this regard, Vertino et al. recently reported that myoblasts isolated from $W n t 10 b$ null mice showed increased adipogenic potential [43].

In our experiments, GDF8 expression slightly increased with myofibre formation, but was clearly upregulated in human satellite cells cultured in AM, independently of the presence of rosiglitazone. These observations confirm the hypothesis that myostatin could regulate the fate of muscle stem cells, promoting their commitment to the adipogenic lineage and inhibiting myogenesis as previously shown in a multipotent mesenchymal cell line [16].

Therefore, even if a complex balance of stimulatory and inhibitory signals determines the progression of human 
satellite cells through a particular lineage, our data suggest that PPARG activation could represent the central event of human satellite cell adipogenic differentiation, while WNT10B and myostatin possibly only act as regulators of this process. Nevertheless, we are aware that measurements of the gene expression profile do not necessarily imply similar changes in protein production and activity.

In the present work, we have clearly shown the adipogenic potential of human satellite cells, and this could explain the origin of mature adipocytes within myofibres or within the intermuscular space. Obesity, type 2 diabetes [1-3] and ageing-related sarcopenia [44] are characterised by 'fatty muscle'. All of these pathological conditions are associated with insulin resistance and it is possible to hypothesise that the presence of fat cells close to muscle cells may directly influence their metabolism and insulin sensitivity through the delivery of metabolites, adipocytokines and inflammatory factors.

Rosiglitazone treatment in itself did not induce any fat conversion in human satellite cells, but greatly enhanced their adipogenic potential triggered by the addition of a specific medium permissive of adipogenesis. However, rosiglitazone is able to induce a more favourable adipocytokine expression profile (higher $A D I P O Q$, lower $L E P$, elevated $P B E F 1$ and no $R E T N$ ) in adipocytes derived from human satellite cells. This effect could modify muscle insulin sensitivity in a paracrine manner. Thus thiazolidinediones, which are able to increase fatty acid disposal and oxidation in skeletal muscle [45], could counteract the worsening effect both of increased intramyocellular triglyceride content and of the presence of fat cells within muscle fibres.

Acknowledgements The excellent technical assistance of $\mathrm{M}$. Tormene and S. Leandri is greatly appreciated. This work was supported by the following grants: (1) from the Ministry of Education, Universities and Research (MIUR): RBNE01KCX4_008 MIUR-FIRB，2003061834_006 MIUR-PRIN; (2) from Regione Veneto: $115 / 03$ to R. Vettor; (3) from the Città della Speranza Foundation, Muscle Project: Pr04/02 to P. De Coppi. The indispensable contribution of S. Galuppo to the processing of adipose tissue and preadipocytes cultures is hugely acknowledged.

Duality of interest statement The authors declare that they have no duality of interest.

\section{References}

1. Greco AV, Mingrone G, Giancaterini A et al (2002) Insulin resistance in morbid obesity: reversal with intramyocellular fat depletion. Diabetes 51:144-151

2. Goodpaster BH, Krishnaswami S, Resnick H et al (2003) Association between regional adipose tissue distribution and both type 2 diabetes and impaired glucose tolerance in elderly men and women. Diabetes Care 26:372-379

3. Gallagher D, Kuznia P, Heshka S et al (2005) Adipose tissue in muscle: a novel depot similar in size to visceral adipose tissue. Am J Clin Nutr 81:903-910
4. Cao B, Huard J (2004) Muscle-derived stem cells. Cell Cycle 3:104-107

5. Wagers AJ, Conboy IM (2005) Cellular and molecular signatures of muscle regeneration: current concepts and controversies in adult myogenesis. Cell 122:659-667

6. Shefer G, Wleklinski-Lee M, Yablonka-Reuveni Z (2004) Skeletal muscle satellite cells can spontaneously enter an alternative mesenchymal pathway. J Cell Sci 117:5393-5404

7. Asakura A, Komaki M, Rudnicki M (2001) Muscle satellite cells are multipotential stem cells that exhibit myogenic, osteogenic, and adipogenic differentiation. Differentiation 68:245-253

8. Teboul L, Gaillard D, Staccini L, Inadera H, Amri EZ, Grimaldi PA (1995) Thiazolidinediones and fatty acids convert myogenic cells into adipose-like cells. J Biol Chem 270:28183-28187

9. Rosen ED, Spiegelman BM (2001) PPARgamma: a nuclear regulator of metabolism, differentiation, and cell growth. J Biol Chem 276:37731-37734

10. Kershaw EE, Flier JS (2004) Adipose tissue as an endocrine organ. J Clin Endocrinol Metab 89:2548-2556

11. Tontonoz P, Hu E, Spiegelman BM (1994) Stimulation of adipogenesis in fibroblasts by PPAR gamma 2, a lipid-activated transcription factor. Cell 79:1147-1156

12. Hu E, Tontonoz P, Spiegelman BM (1995) Transdifferentiation of myoblasts by the adipogenic transcription factors PPAR gamma and C/EBP alpha. Proc Natl Acad Sci USA 92:9856-9860

13. Tontonoz P, Hu E, Spiegelman BM (1995) Regulation of adipocyte gene expression and differentiation by peroxisome proliferator activated receptor gamma. Curr Opin Genet Dev 5:571-576

14. Ross SE, Hemati N, Longo KA et al (2000) Inhibition of adipogenesis by Wnt signaling. Science 289:950-953

15. Bennett CN, Ross SE, Longo KA et al (2002) Regulation of Wnt signaling during adipogenesis. J Biol Chem 277:30998-31004

16. Artaza JN, Bhasin S, Magee TR et al (2005) Myostatin inhibits myogenesis and promotes adipogenesis in $\mathrm{C} 3 \mathrm{H} 10 \mathrm{~T}(1 / 2)$ mesenchymal multi-potent cells. Endocrinology 146:3547-3557

17. McCroskery S, Thomas M, Maxwell L, Sharma M, Kambadur R (2003) Myostatin negatively regulates satellite cell activation and self-renewal. J Cell Biol 162:1135-1147

18. McPherron AC, Lee SJ (2002) Suppression of body fat accumulation in myostatin-deficient mice. J Clin Invest 109:595-601

19. Zimmers TA, Davies MV, Koniaris LG et al (2002) Induction of cachexia in mice by systemically administered myostatin. Science 296:1486-1488

20. Kim HS, Liang L, Dean RG, Hausman DB, Hartzell DL, Baile CA (2001) Inhibition of preadipocyte differentiation by myostatin treatment in 3T3-L1 cultures. Biochem Biophys Res Commun 281:902-906

21. Rosenblatt JD, Lunt AI, Parry DJ, Partridge TA (1995) Culturing satellite cells from living single muscle fiber explants. In Vitro Cell Dev Biol Anim 31:773-779

22. Bonavaud S, Agbulut O, D'Honneur G, Nizard R, Mouly V, Butler-Browne G (2002) Preparation of isolated human muscle fibers: a technical report. In Vitro Cell Dev Biol Anim 38: $66-72$

23. Milan G, Dalla Nora E, Pilon C et al (2004) Changes in muscle myostatin expression in obese subjects after weight loss. J Clin Endocrinol Metab 89:2724-2727

24. Bosch P, Musgrave DS, Lee JY et al (2000) Osteoprogenitor cells within skeletal muscle. J Orthop Res 18:933-944

25. Rochat A, Fernandez A, Vandromme $M$ et al (2004) Insulin and wnt1 pathways cooperate to induce reserve cell activation in differentiation and myotube hypertrophy. Mol Biol Cell 15: 4544-4555

26. Muscat GE, Mynett-Johnson L, Dowhan D, Downes M, Griggs R (1994) Activation of myoD gene transcription by 3,5,3'-triiodo-L- 
thyronine: a direct role for the thyroid hormone and retinoid $\mathrm{X}$ receptors. Nucleic Acids Res 22:583-591

27. Park KS, Ciaraldi TP, Lindgren K et al (1998) Troglitazone effects on gene expression in human skeletal muscle of type II diabetes involve up-regulation of peroxisome proliferator-activated receptor-gamma. J Clin Endocrinol Metab 83:2830-2835

28. Kausch C, Krutzfeldt J, Witke A et al (2001) Effects of troglitazone on cellular differentiation, insulin signaling, and glucose metabolism in cultured human skeletal muscle cells. Biochem Biophys Res Commun 280:664-674

29. Rosen ED, Sarraf P, Troy AE et al (1999) PPAR gamma is required for the differentiation of adipose tissue in vivo and in vitro. Mol Cell 4:611-617

30. Kallen CB, Lazar MA (1996) Antidiabetic thiazolidinediones inhibit leptin (ob) gene expression in 3T3-L1 adipocytes. Proc Natl Acad Sci USA 93:5793-5796

31. Patel NG, Holder JC, Smith SA, Kumar S, Eggo MC (2003) Differential regulation of lipogenesis and leptin production by independent signaling pathways and rosiglitazone during human adipocyte differentiation. Diabetes 52:43-50

32. Fukuhara A, Matsuda M, Nishizawa M et al (2005) Visfatin: a protein secreted by visceral fat that mimics the effects of insulin. Science 307:426-430

33. Berndt J, Kloting N, Kralisch S et al (2005) Plasma visfatin concentrations and fat depot-specific mRNA expression in humans. Diabetes 54:2911-2916

34. Steppan CM, Bailey ST, Bhat S et al (2001) The hormone resistin links obesity to diabetes. Nature 409:307-312

35. Choi KC, Ryu OH, Lee KW et al (2005) Effect of PPAR-alpha and -gamma agonist on the expression of visfatin, adiponectin, and TNF-alpha in visceral fat of OLETF rats. Biochem Biophys Res Commun 336:747-753
36. Nagaev I, Smith U (2001) Insulin resistance and type 2 diabetes are not related to resistin expression in human fat cells or skeletal muscle. Biochem Biophys Res Commun 285: 561-564

37. Savage DB, Sewter CP, Klenk ES et al (2001) Resistin/Fizz3 expression in relation to obesity and peroxisome proliferatoractivated receptor-gamma action in humans. Diabetes 50: 2199-2202

38. Janke J, Engeli S, Gorzelniak K, Luft FC, Sharma AM (2002) Resistin gene expression in human adipocytes is not related to insulin resistance. Obes Res 10:1-5

39. Cossu G, Borello U (1999) Wnt signaling and the activation of myogenesis in mammals. Embo J 18:6867-6872

40. Ridgeway AG, Petropoulos H, Wilton S, Skerjanc IS (2000) Wnt signaling regulates the function of $\mathrm{MyoD}$ and myogenin. J Biol Chem 275:32398-32405

41. Taylor-Jones JM, McGehee RE, Rando TA, Lecka-Czernik B, Lipschitz DA, Peterson CA (2002) Activation of an adipogenic program in adult myoblasts with age. Mech Ageing Dev 123: 649-661

42. Christodoulides C, Scarda A, Granzotto M et al (2006) WNT10B mutations in human obesity. Diabetologia 49:678-684

43. Vertino AM, Taylor-Jones JM, Longo KA et al (2005) Wnt10b deficiency promotes coexpression of myogenic and adipogenic programs in myoblasts. Mol Biol Cell 16:2039-2048

44. Kirkland JL, Tchkonia T, Pirtskhalava T, Han J, Karagiannides I (2002) Adipogenesis and aging: does aging make fat go MAD? Exp Gerontol 37:757-767

45. Cha BS, Ciaraldi TP, Park KS, Carter L, Mudaliar SR, Henry RR (2005) Impaired fatty acid metabolism in type 2 diabetic skeletal muscle cells is reversed by PPARgamma agonists. Am J Physiol Endocrinol Metab 289:E151-E159 